\title{
Manufacturing and Properties of Multifunctional Honeycomb Adsorbent with Volatile Organic Compound Adsorption and Catalytic Oxidation
}

\author{
Yoon-Jong Yoo ${ }^{1 *}$, Minwhee $\mathrm{Cho}^{2}$, Bongbeen $\mathrm{Yim}^{2}$ and Hyunjae $\mathrm{Lee}^{2}$ \\ ${ }^{1}$ Korea Institute of Energy Research, Daejeon 34129, Republic of Korea \\ ${ }^{2}$ Enbion Ltd, Daejeon 34026, Republic of Korea
}

\begin{abstract}
This paper examines the manufacture and properties of honeycomb adsorbent capable of volatile organic compound (VOC) adsorption and catalytic oxidation. A sheet $0.25 \mathrm{~mm}$ thick consisting mainly of ceramic fibers and zeolite $Y$ was produced to form a honeycomb with holes of a constant size. A Pt catalyst was then impregnated to analyze toluene adsorption and catalytic oxidation properties. The Pt catalyst was distributed uniformly across the surface of the honeycomb adsorbent, and there was an insignificant amount of adsorption degradation due to the addition of the catalyst. It was also found that the adsorption properties did not change significantly even after repeated room temperature adsorption and high temperature catalyst oxidation cycles. Adsorption amount was 4.5 wt $\%$ when the partial pressure of toluene was $0.5 \mathrm{mmHg}$, and the conversion rate was $98 \%$ at over $245^{\circ} \mathrm{C}$.
\end{abstract}

Keywords: VOC adsorption; Zeolite Y; Honeycomb adsorbent; Catalytic oxidation; Pt catalyst

\section{Introduction}

In the electronics industry, propylene glycol methyl ether acetate (PGMEA) is used as a sensitizing and insulating solvent when manufacturing components [1], while organic solvents such as hexane are used catalytic cracking process [2-4] and toluene volatile organic compounds (VOC) are widely used in the industrial printing and painting processes [5-7]. VOC is a substance that produces ozone in reaction with light when released to the atmosphere, and is known to cause serious side effects such as paralysis and migraines when it enters the body through breathing. Thus, regulations restricting atmospheric VOC emissions are being strengthened, and efficient VOC removal facilities are being demanded to improve industrial working conditions.

Methods such as thermal oxidation, catalytic oxidation $[8,9]$, adsorption and concentration using activated carbon or zeolite $\mathrm{Y}$ and ZSM-5 [10-12] are currently being used to remove low concentrations of VOC at industrial sites. Thermal and catalytic oxidation, which is most commonly used, removes emitted VOC through combustion or a catalytic incinerator. This method is disadvantageous in that the operation and maintenance costs are high, as it continuously requires auxiliary fuel to maintain oxidation temperature.

Another common method is adsorption removal using activated carbon, in which activated carbon adsorbs VOC until saturation and is disposed of, or recycled for reuse, through pressurization or temperature changes. However, this method is disadvantageous in that it requires periodic exchanges of adsorbent and includes a risk of combustion in the activated carbon tower.

Among these various VOC removal methods, a rotary adsorption, concentration and catalytic combustion method using a honeycomb adsorption rotor [13-16] is a relatively efficient technique. This method combines the adsorption and catalytic combustion process, which continuously performs adsorption, recycling and concentration, and cooling processes by rotating the honeycomb adsorption rotor with the adsorbent, and supplies the concentrated VOC resulting from the recycling process to the catalytic converter for combustion. There is nearly no loss of adsorption gas pressure by the cylindrical honeycomb adsorption rotor used in this process, and the large surface area to volume ratio enables efficient reactions between the adsorbent and adsorption gas. It is particularly advantageous in that the method uses the heat from the catalytic combustion of concentrated VOCs, which comes from the recycling process, in the adsorption recycling process, resulting in nearly no auxiliary fuels being used. Nevertheless, since rotary adsorption and catalytic combustion uses two separate adsorbents, a VOC removal facility that operates in a more compact and economical manner is required. This research was conducted to develop a multifunctional honeycomb adsorbent with adsorption and catalyst oxidation features for application in an integrated VOC adsorption and catalytic combustion process.

\section{Experiment Section}

\section{Manufacturing the honeycomb adsorbent}

A $0.25 \mathrm{~mm}$ thick ceramic sheet consisting mainly of zeolite Y (UOP, HISIV-1000) with a $5.5 \mathrm{SiO}_{2} / \mathrm{Al}_{2} \mathrm{O}_{3}$ ratio and ceramic fibers (KCC, Bulk 1260) was manufactured $[17,18]$. The BET surface area determined by adsorption of nitrogen was shown to be $284 \mathrm{~m}^{2} / \mathrm{g}$ and the zeolite $\mathrm{Y}$ content can be determined to be $43 \%$. Two ceramic sheets were molded into a waveshape, with one side having a pitch of $4.0 \mathrm{~mm}$ and height of $1.8 \mathrm{~mm}$, and wound together to create a cylindrical honeycomb adsorbent of a diameter of $98 \mathrm{~mm}$ and length of $150 \mathrm{~mm}$. The honeycomb adsorbent was put to dry in a solution of $10 \mathrm{~nm}$ silica particle solids at $10 \%$, and was dried at $105^{\circ} \mathrm{C}$ and calcinated at $550^{\circ}$ for 1 hour to completely remove the organic matter in the honeycomb adsorbent. The final weight of honeycomb adsorbent was $139.4 \mathrm{~g}$ (Figure 1).

\section{Manufacturing the multifunctional honeycomb adsorbent}

The addition of the Pt catalyst was through the impregnation

*Corresponding author: Yoon-Jong Yoo, Korea Institute of Energy Research, Daejeon 34129, Republic of Korea, Tel: +82-42-860-3118; Fax: +82-42-860-3705; E-mail: yjyou@kier.re.kr

Received August 25, 2018; Accepted September 10, 2018; Published September 20, 2018

Citation: Yoo YJ, Cho M, Yim B, Lee H (2018) Manufacturing and Properties of Multifunctional Honeycomb Adsorbent with Volatile Organic Compound Adsorption and Catalytic Oxidation. J Material Sci Eng 7: 481. doi: 10.4172/2169-0022.1000481

Copyright: ( 2018 Yoo YJ, et al. This is an open-access article distributed under the terms of the Creative Commons Attribution License, which permits unrestricted use, distribution, and reproduction in any medium, provided the original author and source are credited. 


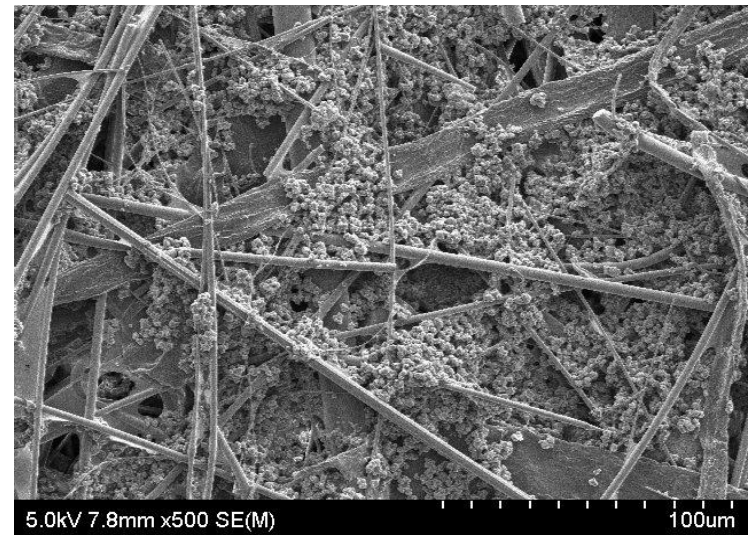

Figure 1: SEM images of ceramic sheet with zeolite $Y(x 500)$

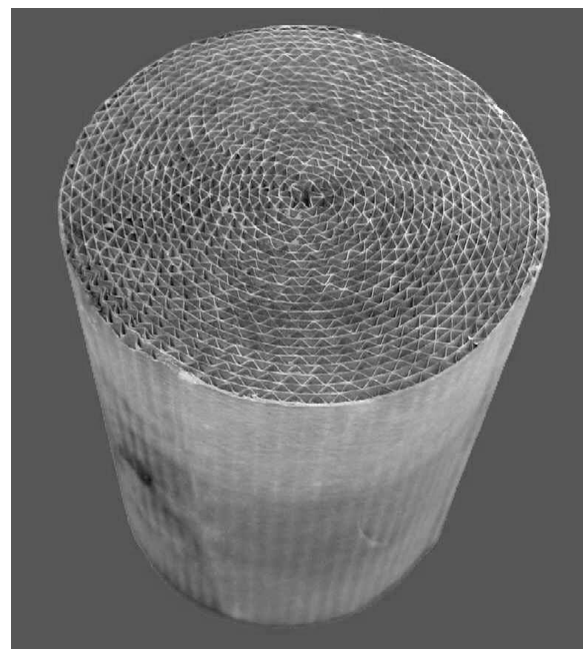

Figure 2: Multifunctional honeycomb adsorbent (size: dia. $98 \mathrm{~mm}$, length 150 $\mathrm{mm})$.

method, and used a zeolite $\mathrm{Y}$ containing honeycomb adsorbent $98 \mathrm{~mm}$ in diameter and $150 \mathrm{~mm}$ in length as the catalyst carrier. It was deposited in a 0.005 mole Tetraammineplatinum (II) Chloride $\left[\mathrm{Pt}\left(\mathrm{NH}_{3}\right)_{4} \mathrm{CL}_{2}\right]$ solution for 30 minutes. Then it was dried at $70^{\circ}$ for 24 hours, and kept in a reactor at $320^{\circ}$ at an oxygenation rate of $S V=30,000 \mathrm{~h}^{-1}$ and heating rate of $0.5^{\circ} \mathrm{C} / \mathrm{min}$ for 2 hours. It was then reduced by heating up to $300^{\circ} \mathrm{C}$ with hydrogen $10 \%$ (nitrogen balance) as the reduction gas at flow rate of $\mathrm{SV}=30,000 \mathrm{~h}^{-1}$ and heating rate of $1.7^{\circ} \mathrm{C} / \mathrm{min}$. The final amount of $\operatorname{Pt}(0)$ catalyst loaded was $0.911 \mathrm{wt} \%$ of honeycomb adsorbent (Figure 2) [19,20].

\section{Evaluation of the adsorptive and catalytic reactions of the multifunctional honeycomb adsorbent}

The apparatus to evaluate the toluene adsorption and catalytic reaction properties of the multifunctional honeycomb adsorbent containing zeolite $\mathrm{Y}$ and $\mathrm{Pt}(0)$ catalyst is depicted in Figure 3. As shown in the figure, after the multifunctional honeycomb adsorbent was charged in the reaction tower, thermocouples were installed at the entrance (T1), middle (T2), and exit (T3) to analyze the temperature changes in real-time. Furthermore, the VOC concentration before and after the reaction tower was also analyzed in real-time through the use of a total hydrocarbon analyzer (HORIBA THC-5100). In addition, the

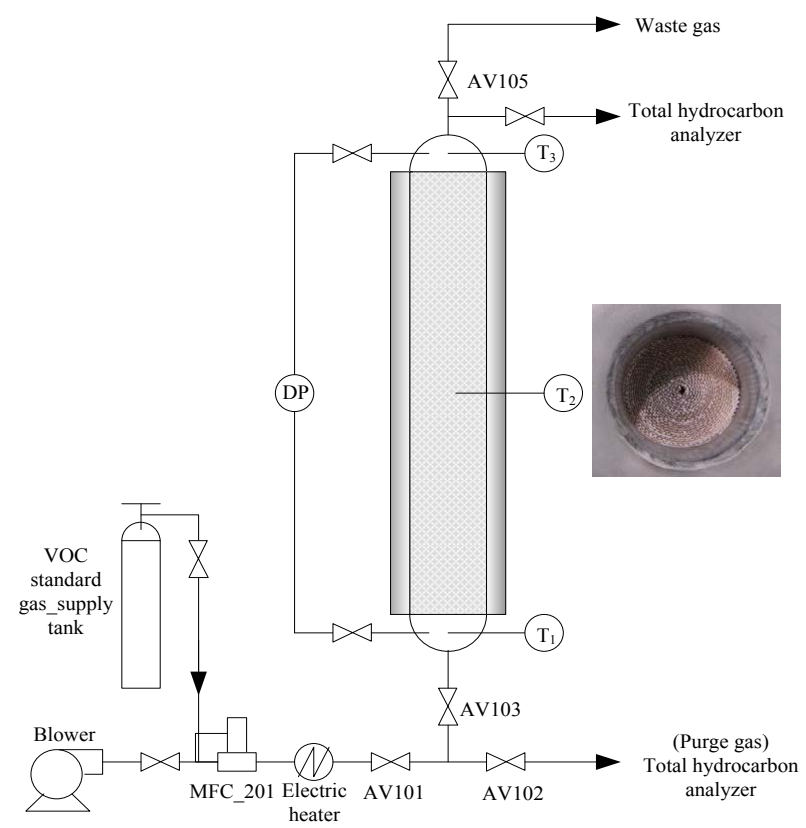

Figure 3: Diagram of the multifunctional honeycomb adsorbent evaluator

adsorption and catalytic combustion airflow rates were kept uniform through the use of a mass flow controller, and the multifunctional honeycomb adsorbent was activated before the adsorption test by supplying external air that was heated to $200^{\circ} \mathrm{C}$ by a blower to the multifunctional honeycomb adsorbent for 30 minutes. The adsorption process controlled VOC concentrations by mixing standard toluene gas with the uniform supply of external air supplied by the blower. When valves AV101, AV103, and AV 105 were opened, the VOC contaminated air went through the multifunctional honeycomb adsorbent within the reactor to be adsorbed, and was then emitted. For the catalytic combustion reaction, external air was heated to $300^{\circ} \mathrm{C}$ using an electric heater after the adsorption process, whereupon the temperature of the catalyst layer and the concentrations at the exit of the reactor tower were analyzed in real-time [21-23].

\section{Results and Discussion}

\section{Surface characteristics of the honeycomb adsorbent}

The surface characteristics of the multifunctional honeycomb adsorbent were analyzed through SEM and EDS mapping (Figures 4 and 5). As shown in Figure 1, on the surface of the ceramic sheet containing zeolite $\mathrm{Y}$, the zeolite $\mathrm{Y}$ particles are evenly distributed around the ceramic fibers that form the frame. The robust binding of ceramic fiber and zeolite Y particles due to silica binders prevented the loss of gases being processed. Additionally, Figure 5, which shows the EDS mapping of Figure 4 in order to check the distribution of $\mathrm{Pt}$ catalyst on the surface of the ceramic sheet, shows an even distribution overall, indicating successful catalyst loading through adsorption.

\section{Toleune adsorption properties of the honeycomb adsorbent}

Figure 6 shows the results of measuring the toluene adsorption properties of the honeycomb adsorbent device using a gravimetric gas adsorption measuring device, the magnetic suspension balance (30G-500P, Rubotherm). As shown by the two comparative graphs, the adsorption equilibrium rate before and after the addition of $\mathrm{Pt}$ is nearly 


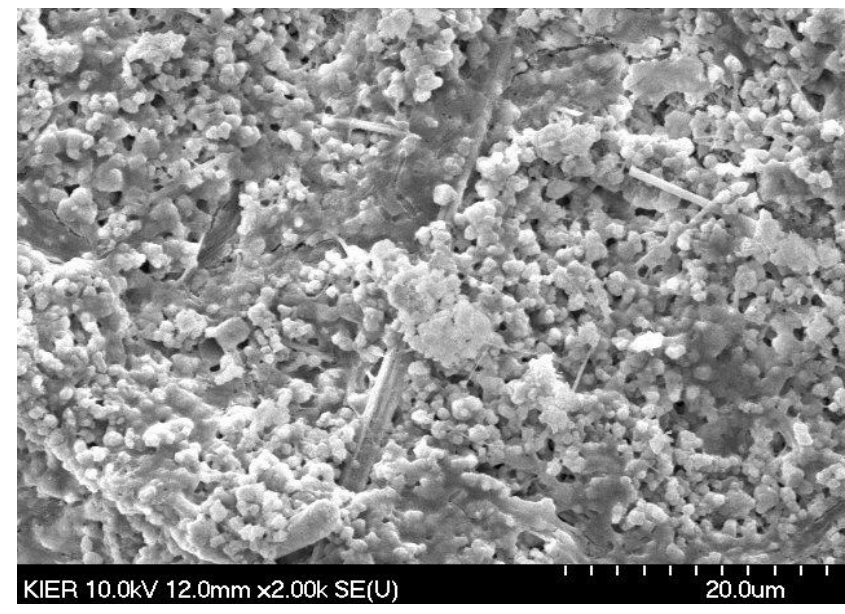

Figure 4: SEM image of the surface of the multifunctional honeycomb adsorbent $(x 2,000)$.

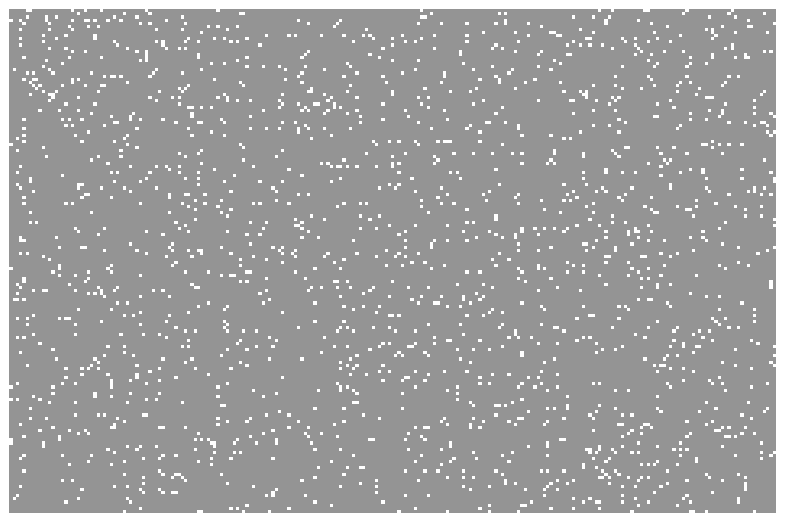

Pt. La1

Figure 5: PT distribution on the multifunctional honeycomb adsorbent by EDS mapping.

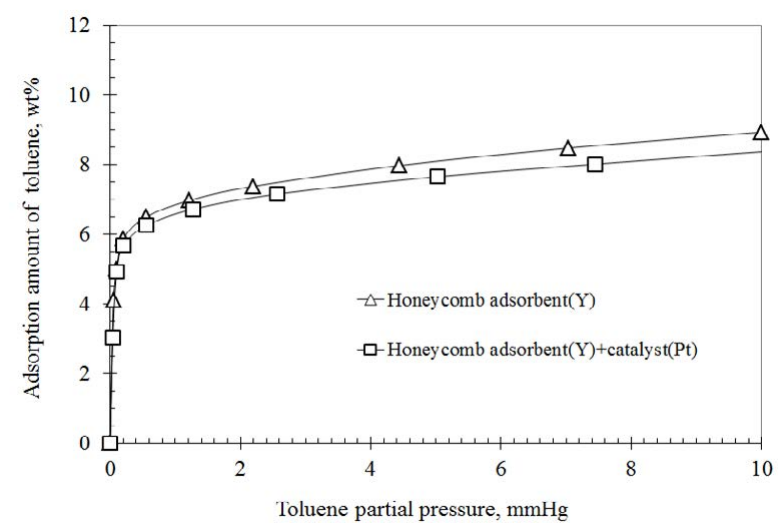

Figure 6: Toluene adsorption equilibrium rate of honeycomb adsorbent before and after Pt catalyst addition.

identical. That is, the adsorption property of zeolite $\mathrm{Y}$ is maintained throughout the process of adding Pt to the honeycomb adsorbent containing zeolite $\mathrm{Y}$. The use condition for the multifunctional honeycomb adsorbent with VOC adsorptive and catalytic oxidation features that this research aims to develop is a VOC concentration below $300 \mathrm{ppm}$, which is relevant to toluene pressures under 0.2 $\mathrm{mmHg}$. Therefore, when actually applied to the VOC removal process, the honeycomb adsorbent adsorptive catalytic oxidation device that was created by this research appears to experience no degradation of adsorption efficiency due to the addition of Pt catalyst.

The results of the analysis of the honeycomb adsorbent's adsorption and desorption properties with regard to toluene polluted air, which was used to design the actual VOC adsorption removal process, is presented in Figure 7. As shown in the graph, when toluene polluted air at $340 \mathrm{ppm}$ was supplied at $40 \mathrm{Nl} / \mathrm{min}$, toluene began to be desorbed in 8 minutes, and became equal to the concentration at the entrance in roughly 23 minutes. A notable result is that the adsorption and desorption properties before and after loading the catalyst are nearly identical, similar to the recorded adsorption equilibrium. Furthermore, when assuming that the rotary VOC removal process uses a cylindrical honeycomb adsorbent at a rotation speed of $4 \mathrm{rph}$, approximately 36 ppm of the toluene polluted air is desorbed since the adsorption zone is 12 minutes. Under identical conditions, the adsorption removal efficiency is expected to be about $89.5 \%$, and the concentration of polluted air or throughput needs to be reduced by $10 \%$ for increased adsorption removal efficiency.

\section{Catalytic combustion properties of honeycomb adsorbent}

Figure 8 shows the experimental results of catalyst layer temperature changes on the conversion rates. That is, it shows the conversion rates following temperature changes in the reactor catalyst layer when the honeycomb adsorbent has been placed in the reactor and the concentration of toluene polluted air was changed from 500, $1000,1500 \mathrm{ppm}$ while being supplied at a rate of 5,000 $\mathrm{h}^{-1}$. As shown in the graph, at a catalyst layer temperature of $150 \mathrm{C}$, the conversion rate $(\gamma)$ following catalytic combustion increased to $87 \%, 97 \%$ and $98 \%$, respectively. The low conversion rate of $87 \%$ for toluene polluted air at $500 \mathrm{ppm}$ is expected to be the result of the catalyst layer temperature being lower than that of the stable reaction temperature coupled with insufficient temperature increases to the catalyst layer by catalytic combustion. When the temperature of the catalytic layer exceeded $200^{\circ} \mathrm{C}$, conversion rates in toluene polluted air at $500 \mathrm{ppm}(\circ, \Delta)$ were all over $98 \%$, and identical results were observed even when increasing the concentration of polluted air.

Figure 9 shows the results of continuous analysis of toluene

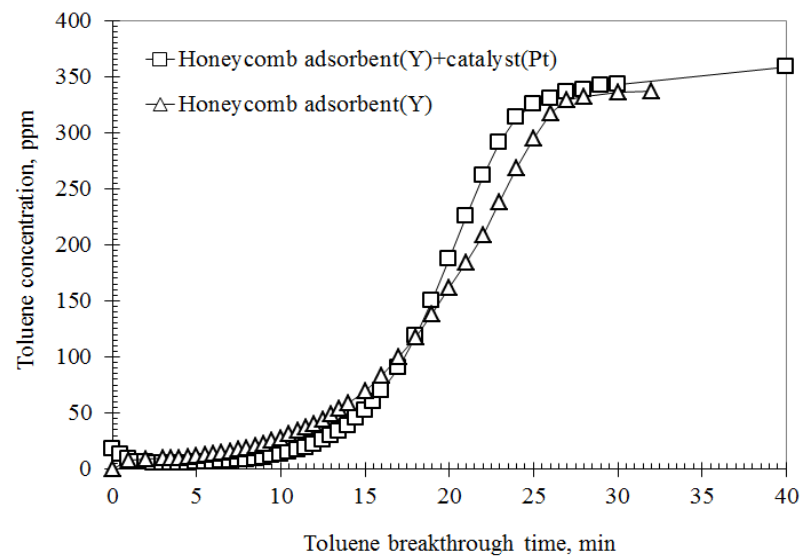

Figure 7: Toluene polluted air adsorption properties of the honeycomb adsorbent before and after the addition of Pt catalyst. 


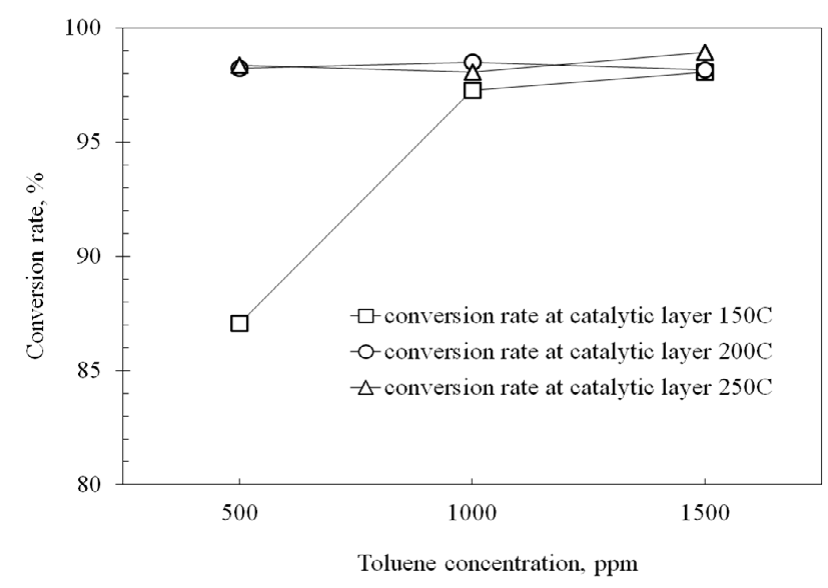

Figure 8: Comparison of combustion conversion rates following early temperature changes during the catalytic reactions of the multifunctional honeycomb adsorbent.

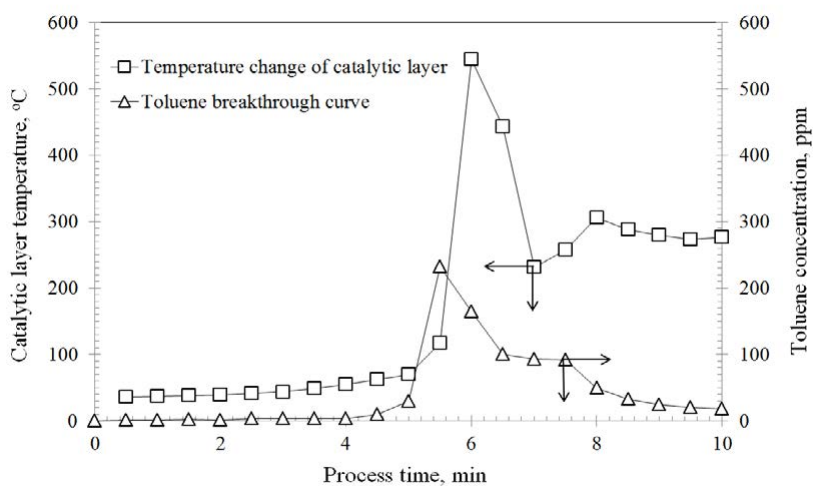

Figure 9: Toluene adsorption and catalytic combustion properties following temperature changes to the multifunctional honeycomb adsorbent.

adsorption and catalytic oxidation by the multifunctional honeycomb adsorbent. Both the toluene concentration at the reactor's exit and the temperature of the multifunctional honeycomb adsorbent were analyzed after placing the multifunctional honeycomb adsorbent in the reactor, sending toluene polluted air at $1025 \mathrm{ppm}$ at a rate of 5000 $\mathrm{h}^{-1}$, and increasing the temperature of the catalyst layer from $35^{\circ} \mathrm{C}$ to $300^{\circ} \mathrm{C}$. This resulted in the concentration of toluene being emitted by adsorption remaining low at $5 \mathrm{ppm}$ when the temperature of the catalyst layer was below $60^{\circ} \mathrm{C}$, for $99.5 \%$ removal efficiency. Afterwards, when the adsorption and catalytic oxidation reactions failed to occur due to the effects of rising temperatures in the catalytic layer and adsorption saturation, the concentration of toluene emissions sharply increased to about $230 \mathrm{ppm}$, but showed stabilization in temperature and removal efficiency after catalytic combustion following a rise in catalyst layer temperature to over $150^{\circ} \mathrm{C}$.

The results of such analysis led to the design of the VOC removal process using a multifunctional honeycomb adsorbent as depicted in Figure 10. As shown in the figure, the multifunctional honeycomb adsorbent was divided into a ratio of adsorption zone (8): catalytic combustion zone(1): cooling zone(1) through the use of external equipment. In addition, adsorption of polluted air occurs at room temperature by supplying polluted air to the adsorption zone while

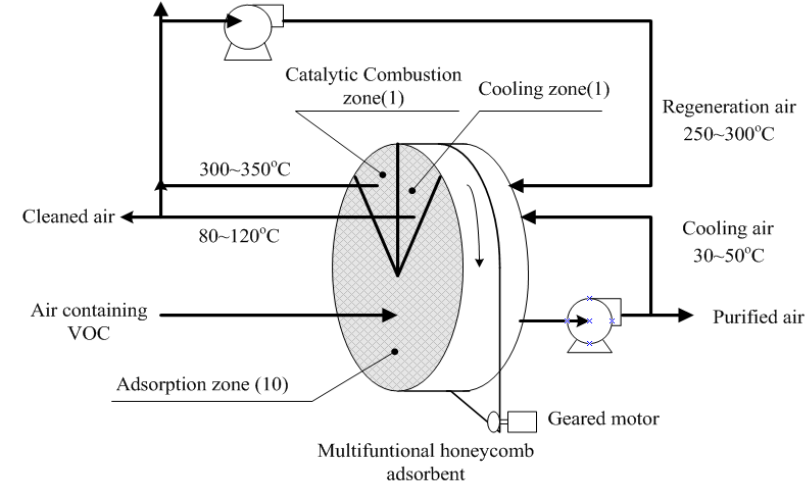

Figure 10: Example of a rotary VOC adsorption-catalytic combustion process using a multi-functional honeycomb adsorbent.

rotating it at a rate of $3 \sim 4 \mathrm{rph}$. After adsorption saturation, the polluted air is moved to the catalytic combustion zone where the catalytic combustion reaction occurs via air at a temperature of roughly $250^{\circ} \mathrm{C}$; it is emitted after catalytic combustion, with temperatures rising by roughly $100^{\circ} \mathrm{C}$ as a result of the catalytic combustion. The emitted air is then mixed again with the cooling air at the exit in a uniform ratio, to be recirculated as the air needed for the catalytic reaction. The catalytic combustion zone is heated by the catalytic combustion reaction; this heated zone can be cooled by supplying some of the room temperature air that is expelled after adsorption. This adsorptioncatalytic combustion-cooling process is only possible by the use of the multifunctional honeycomb adsorbent, and can be a much more efficient process for removing VOC contaminated air.

\section{Conclusion}

To develop a multifunctional honeycomb adsorbent capable of VOC adsorption and catalytic combustion, a ceramic sheet containing adsorbents was produced, and a catalyst was added to the honeycomb adsorbent that utilized these sheets. The manufacturing process was optimized, and an analysis of the adsorption properties of such a manufactured multifunctional honeycomb adsorbent showed nearly equal toluene adsorption amounts before and after the addition of the catalyst. Furthermore, analysis of the catalytic combustion confirmed that the manufacture of a multifunctional honeycomb adsorbent with adsorption and catalytic oxidation properties was successful in that the conversion rate exceeded $98 \%$ when the temperature of the catalyst layer was over $200^{\circ} \mathrm{C}$. Such a multifunctional honeycomb adsorbent can simply a rotary VOC removal process that involves adsorption heated recycling and concentration - catalytic combustion - cooling into a process that only involves adsorption - heating and catalytic combustion - cooling, thus enabling more compact facilities and economical system management.

\section{Acknowledgment}

This research is supported by Korea of Environmental Industry \& Technology Institute (KEITI), Korea Ministry of Environment (MOE) as an "Advancement of Environmental Industry Technology Development Program" (PN: 2016000110001).

\section{References}

1. Chaniago YD, Harvianto GR, Bahadori A, Lee M (2016) Enhanced recovery of PGME and PGMEA from waste photoresistor thinners by heterogeneous azeotropic dividing-wall column. Process Saf Environ Prot 103: 413-423.

2. Yamaguchi A, Jin D, Ikeda T, Sato K, Hiyoshi N, et al. (2015) Effect of steam during catalytic cracking of $n$-hexane using P-ZSM- 5 catalyst. Catal Commun 69: 20-24. 
Citation: Yoo YJ, Cho M, Yim B, Lee H (2018) Manufacturing and Properties of Multifunctional Honeycomb Adsorbent with Volatile Organic Compound Adsorption and Catalytic Oxidation. J Material Sci Eng 7: 481. doi: 10.4172/2169-0022.1000481

3. Wang Y, Yokoi T, Namba S, Kondo JN, Tatsumi T (2015) Catalytic cracking of $n$-hexane for producing propylene on MCM-22 zeolites. Appl Catal A 504: 192-202.

4. Li X, Li W, Rezaei F, Rownaghi A (2018) Catalytic cracking of n-hexane for producing light olefins on 3D-printed monoliths of MFI and FAU zeolites. Chem Eng J 333: 545-553.

5. Caselli M, de Gennaro G, Saracino MR, Tutino M (2009) Indoor contaminants from newspapers: VOCs emissions in newspaper stands. Environ Res 109 149-157.

6. Jafari S, Ghorbani-Shahna F, Bahrami A, Kazemian H (2018) Adsorptive removal of toluene and carbon tetrachloride from gas phase using Zeolitic Imidazolate Framework-8: Effects of synthesis method, particle size, and pretreatment of the adsorbent. Microporous Mesoporous Mater 268: 58-68.

7. Qin C, Guo H, Liu P, Bai W, Yan D (2018) J. of Indus. And Engine. Chem., 63,449

8. Kamal MS, Razzak SA, Hossain MM (2016) Catalytic oxidation of volatile organic compounds (VOCs)-A review. Atmos Environ 140: 117-134.

9. Pan KL, Pan GT, Chong S, Chang MB (2018) Removal of VOCs from gas streams with double perovskite-type catalysts. J Environ Sci 69: 205-216.

10. Zhang X, Gao B, Creamer AE, Cao C, Li Y (2017) Adsorption of VOCs onto engineered carbon materials: A review. J Hazard Mater 338: 102-123.

11. Kullavanijaya E, Trimm DL, Cant NW (2000) Adsocat: Adsorption/catalytic combustion for VOC and odour control. In Studies in Surface Science and Catalysis. Elsevier 130: 569-574.

12. Guillemot M, Mijoin J, Mignard S, Magnoux P (2007) Volatile organic compounds (VOCs) removal over dual functional adsorbent/catalyst system. Appl Catal B 75: 249-255.

13. Kuma T (1998) J Chem Eng Japan 24: 248.
14. Yamauchi $\mathrm{H}$, Kodama A, Hirose $\mathrm{T}$, Okano $\mathrm{H}$, Yamada KI (2007) Performance of VOC abatement by thermal swing honeycomb rotor adsorbers. Ind Eng Chem Res 46: 4316-4322.

15. Yoo YJ, Kim HS, Han MH (2005) Toluene and MEK adsorption behavior of the adsorption system using honeycomb adsorption rotor. Sep Sci Technol 40 1635-1651.

16. Yoo YJ, Kim HS, Han MH, Jang GE (2000) J Kor Theories \& App Chem 6: 436

17. Yoo YJ, Kim HS, Han MH, Jang GE (2003) Toluene and MEK Adsorption Behaviors of Rotary Adsorption System with Zeolite-Impregnated Honeycomb Rotor Installed. J Kor Ind Eng Chem14: 852

18. Yoo YJ, Kim JS, Kim HS, Ahn YS, Han MH, et al. (2002) Dispersion characteristics of slurry and preparation of ceramic paper. J Korean Ceram Soc 39: 1042-1047.

19. Swetha G, Gopi T, Shekar SC, Ramakrishna C, Saini B, et al. (2017) Combination of adsorption followed by ozone oxidation with pressure swing adsorption technology for the removal of VOCs from contaminated air streams. Chem Eng Res Des 117: 725-732.

20. Cecchini JP, Serra RM, Barrientos CM, Ulla MA, Galván MV, et al. (2011) Ceramic papers containing $Y$ zeolite for toluene removal. Microporous Mesoporous Mater 145: 51-58.

21. Ribeiro FH, Chow M, Dallabetta RA (1994) Kinetics of the complete oxidation of methane over supported palladium catalysts. J Catal 146: 537-544.

22. Lee J, Kim Y (2012) Preparation of polyethylene with controlled bimodal molecular weight distribution using zirconium complexes. J Ind Eng Chem 18: $429-432$.

23. Rabo JA, Schoonover MW (2001) Early discoveries in zeolite chemistry and catalysis at Union Carbide, and follow-up in industrial catalysis. Appl Catal A 222: $261-275$. 